\title{
FULLY AUTOMATED LIGHT PRECIPITATION DETECTION FROM MPLNET AND EARLINET NETWORK LIDAR MEASUREMENTS.
}

\author{
Simone Lolli1, *, Gemine Vivone4, Ellsworth J. Welton2, Jasper R. Lewis3, James R. Campbell5, \\ Michael Sïcard6, Adolfo Comeron6, Gelsomina Pappalardo1 \\ ${ }_{1}$ CNR, Institute of Methodologies for Environmental Analysis, 85050 Tito Scalo (PZ), Italy. \\ 2NASA Goddard Flight Space Center, CODE 612, Greenbelt, MD 20771, USA \\ 3JCET-UMBC, 1000 Hilltop Cir, Baltimore, MD 21250, USA \\ 4 Univ. of Salerno, Dept. of Inform. Engin., Electr. Engin. and App. Maths., 84084 Fisciano (SA), Italy \\ 5 Naval Research Laboratory, 7 Grace Hopper Ave, Monterey, CA 93943, USA \\ o RSLAB, Univ. Politec de Catalunya, Carrer de Jordi Girona, 1, 3, 08034 Barcelona, Spain
}

\section{*Email:simone.lolli@imaa.cnr.it}

\begin{abstract}
The water cycle strongly influence life on Earth and precipitation especially modifies the atmospheric column thermodynamics through the evaporation process and serving as a proxy for latent heat modulation. For this reason, a correct light precipitation parameterization at global scale, it is of fundamental importance, bedsides improving our understanding of the hydrological cycle, to reduce the associated uncertainty of the global climate models to correctly forecast future scenarios. In this context we developed a full automatic algorithm based on morphological filters that, once operational, will make available a new rain product for the NASA Micropulse Lidar Network (MPLNET) and the European Aerosol Research Lidar Network (EARLINET) in the frame of WMO GALION Project
\end{abstract}

\section{INTRODUCTION}

In the last decades, thanks to internet, groundbased network of instruments started to develop to measure important climate-related variables, among which the most important the aerosol optical and microphysical properties measured by lidar instruments, developed after $\mathrm{CO}_{2}$ laser invention [1]. The NASA Micropulse Lidar Network (MPLNET, [2], [3], [4]) is a global network of homogeneous elastic lidar instruments that monitor the atmosphere 24/24 under any meteorological condition. Version 3 Level 1 and 2 MPLNET products provide, among others, aerosol and cloud backscattering and extinction atmospheric profiles [5], [6] and the boundary layer height, used to characterize aerosol sources and transport [7]. Elastic, multi-wavelength and
Doppler [8] lidar measurements containing raining events are unjustifiably disregard. Precipitations, which modifies the atmospheric column thermodynamics, are crucial to reduce global model uncertainty to forecast future scenarios [9]. [10]. In this work we present the first tests of the automatic light rain detection algorithm developed to be operative on NASA MPLNET network to characterize light precipitation characteristics at global scale.

\section{METHODOLOGY}

Previous studies demonstrated that it is possible to quantitatively assess light rain microphysical characteristics using a multi-wavelength lidar [11], [12] and an elastic lidar and a disdrometer [13]. However, for the latter applications, the rain episodes were eye detected. For this reason, the need to develop an automatic algorithm to be implemented operationally for future product release [14]. The implemented methodology employs vertical and horizontal morphological filters to detect the rain episodes, i.e rain start, rain stop, and relative cloud height. The algorithm uses as input the $24 \mathrm{hr}$ depolarization channel range corrected signal.

\section{RESULTS}

An example on how the rain looks on lidar data is 


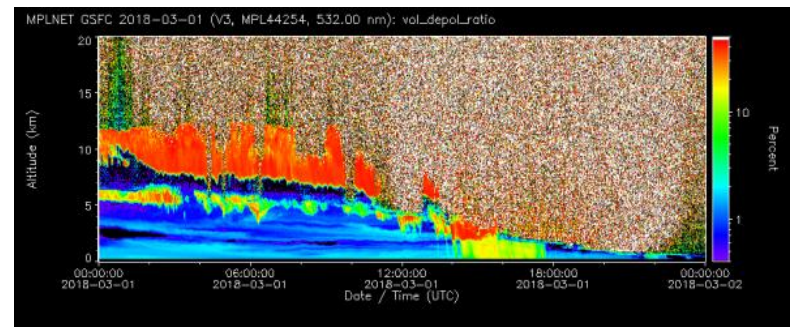

Figure. 1 Depolarization Channel from MPLNET GSFC station on March, 1st 2018. A rain event is clearly detected from about 1400 to 1800 UTC.

showed in Figure 1 representing the range corrected depolarization channel from NASA GSFC permanent observation station on March, 1 st 2018. Multi-layers clouds are clearly visible around $10 \mathrm{~km}$ and $6 \mathrm{~km}$. The cloud base is lowering and starts to rain at $2.5 \mathrm{~km}$ at around $1400 \mathrm{UTC}$ and finishing at around 1745 UTC. A second rain episode is visible at around 2330 UTC.

After testing several edge detectors, the morphological filters produce the best results and were chosen for final implementation. With respect to Figure 1, the algorithm detected the following rain episodes:

\begin{tabular}{|l|l|}
\hline Rain Starts & Rain ends \\
\hline $16: 58$ & $18: 08$ \\
\hline $18: 39$ & $19: 13$ \\
\hline $23: 49$ & $23: 54$ \\
\hline
\end{tabular}

Table 1 Rain episodes on March $1_{s t,} 2018$ at NASA GSFC permanent observational site

The results were verified data from ground-based rain-gauge measurements. The algorithm will be exhaustively tested on MPLNET and EARLINET data, to be further implemented operationally on both networks. The result is encouraging in view of the new constituting network of networks GALION, of the World Meteorological Organization.

\section{ACKNOWLEDGEMENTS}

This study and the NASA Micropulse Lidar Network (MPLNET) are supported by the NASA Radiation Sciences Program (H. Maring)

\section{REFERENCES}

[1] Ciofini, et al.,. "Diffractive optical components for high power laser beam sampling." Journal of Optics A: Pure and Applied Optics 5.3 (2003): 186.

[2] Welton, E.J., J. R. Campbell, J. D. Spinhirne, and V. S. Scott, Global monitoring of clouds and aerosols using a network of micro-pulse lidar systems, Proc. SPIE, 4153, 151-158 (2001)

[3] Campbell, J.R. J.R., D.L. Hlavka, E.J. Welton, C.J. Flynn, D.D. Turner, J.D. Spinhirne, V.S. Scott, and I.H. Hwang. Full-time, Eye-Safe Cloud and Aerosol Lidar Observation at Atmospheric Radiation Measurement Program Sites: Instrument and Data Processing, $J$. Atmos. Oceanic Technol., 19, 431-442 (2002)

[4] Lolli, S., P. Di Girolamo, Principal Component Analysis Approach to Evaluate Instrument Performances in Developing a Cost-Effective Reliable Instrument Network for Atmospheric Measurements. $J$. Atmos. Oceanic Technol., 32, 1642-164 (2015)

[5] Lolli, S., Madonna, F., Rosoldi, M., Campbell, J. R., Welton, E. J., Lewis, J. R., Gu, Y., and Pappalardo, G.: Impact of varying lidar measurement and data processing techniques in evaluating cirrus cloud and aerosol direct radiative effects, Atmos. Meas. Tech., 11, 1639-1651 (2018)

[6] Lolli, S., J.R. Campbell, J.R. Lewis, Y. Gu, J.W. Marquis, B.N. Chew, S. Liew, S.V. Salinas, and E.J. Welton: Daytime Top-of-the-Atmosphere Cirrus Cloud Radiative Forcing Properties at Singapore. J. Appl. Meteor. Climatol., 56, 1249-1257 (2017)

[7] Milroy, C, et al. "An assessment of pseudooperational ground-based light detection and ranging sensors to determine the boundary-layer structure in the coastal atmosphere." Advances in Meteorology 2012 (2012).

[8] Lolli, S., Delaval, A., Loth, C., Garnier, A., and Flamant, P. H.: 0.355-micrometer direct detection wind lidar under testing during a field campaign in consideration of ESA's ADM-Aeolus mission, Atmos. Meas. Tech., 6, 3349-3358 (2013)

[9] Lolli, S., Khor, W. Y., Matjafri, M. Z., \& Lim, H. S. (2019). Monsoon Season Quantitative Assessment of Biomass Burning Clear-Sky Aerosol Radiative Effect at Surface by Ground-Based Lidar Observations in Pulau Pinang, Malaysia in 2014. Remote Sensing, 11(22), 2660.

[10] Campbell, J.R., C. Ge, J. Wang, E.J. Welton, A. Bucholtz, E.J. Hyer, E.A. Reid, B.N. Chew, S. Liew, 
S.V. Salinas, S. Lolli, K.C. Kaku, P. Lynch, M. Mahmud, M. Mohamad, and B.N. Holben,: Applying Advanced Ground-Based Remote Sensing in the Southeast Asian Maritime Continent to Characterize Regional Proficiencies in Smoke Transport Modeling. J. Appl. Meteor. Climatol., 55, 3-22 (2016)

[11] Lolli, S., E.J. Welton, and J.R. Campbell, Evaluating Light Rain Drop Size Estimates from Multiwavelength Micropulse Lidar Network Profiling, $J$. Atmos. Oceanic Tech., 30, 2798-2807 (2013)

[12] Lolli, S., P.D. Girolamo, B. Demoz, X. Li, and E.J. Welton, 2016. Rain evaporation rate estimates from dual-wavelength lidar measurements and intercomparison against a model analytical solution. J. Atmos. Oceanic Tech., DOI: 10.1175/JTECH-D-160146.1 .

[13] Lolli, S.; D’Adderio, L.P.; Campbell, J.R.; Sicard, M.; Welton, E.J.; Binci, A.; Rea, A.; Tokay, A.; Comerón, A.; Barragan, R.; Baldasano, J.M.; Gonzalez, S.; Bech, J.; Afflitto, N.; Lewis, J.R.; Madonna, F. Vertically Resolved Precipitation Intensity Retrieved through a Synergy between the Ground-Based NASA MPLNET Lidar Network Measurements, Surface Disdrometer Datasets and an Analytical Model Solution. Remote Sens., 10, 1102 (2018

[14] Lolli, S., Vivone, G., Lewis, J. R., Sicard, M., Welton, E. J., Campbell, J. R., ... \& Pappalardo, G. (2020). Overview of the New Version 3 NASA MicroPulse Lidar Network (MPLNET) Automatic Precipitation Detection Algorithm. Remote Sensing, 12(1), 71. 